\title{
Small Subunit Ribosomal DNA-Based Phylogenetic Analysis of Foliar Nematodes (Aphelenchoides spp.) and Their Quantitative Detection in Complex DNA Backgrounds
}

\author{
Katarzyna Rybarczyk-Mydłowska, Paul Mooyman, Hanny van Megen, Sven van den Elsen, Mariëtte Vervoort, \\ Peter Veenhuizen, Joop van Doorn, Robert Dees, Gerrit Karssen, Jaap Bakker, and Johannes Helder
}

First, second, third, fourth, fifth, tenth, and eleventh authors: Laboratory of Nematology, Department of Plant Sciences, Wageningen University, Droevendaalsesteeg 1, 6708 PB Wageningen, The Netherlands; sixth author: BLGG AgroXpertus, Binnenhaven 5 6709 PD, 6709 PA Wageningen, The Netherlands; seventh and eighth authors: Flower Bulbs and Nursery Stock-PPO Lisse, Prof. van Slogterenweg 2, 2161 DW Lisse, The Netherlands; and ninth author: Plant Protection Service, Nematology Section, Geertjesweg 15, 6706 EA Wageningen, The Netherlands.

Accepted for publication 2 August 2012.

\begin{abstract}
Rybarczyk-Mydłowska, K., Mooyman, P., van Megen, H., van den Elsen, S., Vervoort, M., Veenhuizen, P., van Doorn, J., Dees, R., Karssen, G., Bakker, J., and Helder, J. 2012. Small subunit ribosomal DNA-based phylogenetic analysis of foliar nematodes (Aphelenchoides spp.) and their quantitative detection in complex DNA backgrounds. Phytopathology 102:1153-1160.

Foliar nematodes, plant-parasitic representatives of the genus Aphelenchoides, constitute a minority in a group dominated by fungivorous species. Distinction between (mostly harmless) fungal feeding Aphelenchoides species and high impact plant parasites such as A. besseyi, A. fragariae, A. ritzemabosi, and A. subtenuis is severely hampered by the scarcity of informative morphological characters, some of which are only observable in specific developmental stages. Poor description of a number

of non-plant-parasitic Aphelenchoides species further complicates identification. Based on (nearly) full-length small subunit ribosomal DNA (SSU rDNA) sequences $(\approx 1,700 \mathrm{bp})$, a phylogenetic tree was generated, and the four target species appeared as distinct, well-supported groups. Notably, this genus does not constitute a monophyletic group: A. besseyi and $A$. ritzemabosi cluster together and they are phylogenetically isolated from A. fragariae, A. subtenuis, and most other fungivorous species. A phylum-wide SSU rDNA framework was used to identify species-specific DNA motifs. For the molecular detection of four plant-parasitic Aphelenchoides species, polymerase chain reaction primers were developed with high, identical annealing temperatures $\left(63^{\circ} \mathrm{C}\right)$. Within the molecular framework presented here, these primers can be used for the rapid screening of plant material and soil for the presence of one or multiple foliar nematode species.
\end{abstract}

Foliar nematodes are the common name of plant-parasitic members of the genus Aphelenchoides. Almost all foliar nematodes feed as ecto- or endoparasites on aboveground plant parts, and some species may cause substantial economic losses in both mono- and dicotyledonous crop species. Aphelenchoides fragariae is the causal agent of strawberry crimp, and apart from strawberry, this nematode is reported to attack over 100 plant species belonging to various families. "White-tip disease" refers to a characteristic whitening of leaf tips of rice as a result of parasitism by $A$. besseyi. However, rice is not its only host; it also reproduces on strawberry ("summer dwarf") and other plant species such as Polianthes tuberosa and Capsicum annuum (9). Another economically important member of the genus Aphelenchoides, the chrysanthemum foliar nematode $A$. ritzemabosi causes a typical brown discoloration of angular sections between large leaf veins, and chrysanthemum and various other members of the Asteraceae are susceptible hosts. An atypical example of a foliar nematode is the root parasite A. subtenuis as it has been shown to feed on roots of narcissus (18). In interaction with other bulbous hosts such as gladiolus, this nematode was found in corms and pseudo-

Corresponding author: J. Helder; E-mail address: Hans.Helder@wur.nl

* The $\boldsymbol{e}$-Xtra logo stands for "electronic extra" and indicates that Figures 1, 2, and 3 appear in color online.

http://dx.doi.org/10.1094/PHYTO-05-12-0114-R

(c) 2012 The American Phytopathological Society stems (17). These foliar nematode species all feed on fungi as well (12). Apart from their possible survival on fungi in absence of a plant host, the management of some of the foliar nematodes is hindered by their desiccation tolerance.

Besides foliar nematodes, the genus Aphelenchoides harbors over 100 mainly mycetophagous species. Species such as $A$. bicaudatus, A. composticola, and A. saprophilus are frequently found in habitats that also harbor plant parasites. Only taxonomic experts are able to distinguish between (often) harmless mycetophagous species and true foliar nematodes on the basis of morphological characteristics. It is noted that the systematics of this genus are unstable; Hunt (12) indicated that "many nominal species are inadequately characterized for reliable recognition and the genus is in urgent need of a major revision" (12).

Many taxonomic classifications suggest a common ancestry between the families Aphelenchoididae (Aphelenchoides being the most speciose genus of the family) and Aphelenchidae (for most recent overview see De Ley et al. [5]). However, molecular phylogenetics based on full-length small subunit ribosomal DNA (SSU rDNA) sequences suggested a sister relationship between the Aphelenchoididae (Aphelenchoides, Laimaphelenchus, and Schistonchus) and the Parasitaphelenchidae (Bursaphelenchus spp.) $(10,28)$, and both families appeared to be only distantly related to the Aphelenchidae (26). The genus Aphelenchoides was shown to be polyphyletic as the foliar nematode species $A$. besseyi and $A$. ritzemabosi together with most Laimaphelenchus species reside in a subclade robustly separated from the other members of the genus Aphelenchoides (26). So far the relatively conserved 
SSU rDNA gene seems to offer sufficient phylogenetic signal for the distinction between Aphelenchoides species (26).

Possibilities to explore the ribosomal DNA cistron for Aphelenchoides detection purposes have been investigated before. Ibrahim et al. (13) amplified the internal transcribed spacers (ITS) and the entire 5.8S gene from eight Aphelenchoides species and looked for restriction fragment length polymorphisms in these $\approx 1,000$-bp fragments. The restriction enzyme $A l u \mathrm{I}$ was most successful for the differentiation of Aphelenchoides species, but failed in the case of $A$. besseyi. More recently, McCuiston et al. (16) concentrated on the ITS1 region ( $\approx 170 \mathrm{bp})$, and on the basis of a framework of 20 ITS1 sequences (including five Aphelenchoides species), A. fragariae-specific polymerase chain reaction (PCR) primers were developed. ITS regions are relatively variable as they are noncoding. This can be advantageous as these regions show high interspecies variation, but among nematodes the intraspecies variation can be considerable as well (16) (Fig. 1). Hence, for detection purposes thorough insight in ITS sequence variation among populations is a prerequisite. To avoid this and to broaden the applicability of assays, tests for the detection of plant-parasitic nematode species are more and more based on coding regions within the nuclear or mitochondrial genome.

Previous results $(3,26,28)$ suggested that SSU rDNA contains sufficient phylogenetic signal for the identification of Aphelenchoides species. Here an alignment of 48 Aphelenchoides SSU rDNA sequences was used in combination with a larger phylumwide framework comprising $\approx 2,500$ nematode taxa. Apart from a phylogenetic analysis, quantitative PCR-based assays are presented for the detection of four foliar nematode species, namely A. besseyi, A. fragariae, A. ritzemabosi, and A. subtenuis. A single PCR program can be used for all assays, and by using phylumwide unique DNA sequence signatures, these four assays are suitable for detection in both simple (plant material) and complex (soil or substrate) DNA backgrounds. It is noted that by far not all (>100) Aphelenchoides species described in literature were included in this paper. In part this is due to the unstable systematic status of this genus and to the very poor description of many species. Hence, specificity of the tests presented here can only be guaranteed within the molecular framework used in this study.

\section{MATERIALS AND METHODS}

Taxon sampling and acquisition of SSU rDNA sequences. Nematode collection and identification, followed by lysis, amplification, and sequencing of two overlapping SSU rDNA fragments were performed as described by Holterman et al. (10). Apart from newly generated sequences, all publicly available (nearly) full-length SSU rDNA data from Aphelenchoididae were included. A full list of rDNA sequences and the corresponding GenBank numbers are given in Figure 1.

Phylogenetic analyses. The SSU rDNA trees were constructed using Bayesian inference and the maximum likelihood (ML) method. For the Bayesian analysis, the alignment was divided into a stem and a loop partition according to the secondary structure. For both partitions, GTR $+\gamma+$ I was used. Four independent runs were made with four Markov chains per run. The program was run for 2 million generations with a sample frequency of 200 generations. The first 60,000 generations were discarded as burnin. The program Tracer v1.4 (23) was used to check the stabilization of likelihood and parameters.

ML analyses, the RAxML-HPC BlackBox program available at the CIPRES Science Gateway V. 3.1 (http://www.phylo. org/sub_sections/portal/), was used (25). The following parameters were chosen: estimated proportion of invariable sites (GTRGAMMA + I), finding best tree using ML search, bootstrapping halted automatically, and printed branch lengths.

Primer design and specificity testing. For the development of SSU rDNA-based detection assays for A. besseyi, A. fragariae, A. ritzemabosi, and A. subtenuis, we essentially followed the procedure as described in Neilson et al. (21). As a starting point, an alignment of approximately 2,500 full-length SSU rDNA sequences was used. The corresponding nematode taxa cover a substantial part of the nematode biodiversity in terrestrial and freshwater habitats in moderate climate zones till genus level. The Linux-based software package ARB (14) was used to identify unique rDNA sequence signatures for each of the four foliar nematode species. PCR primers (Table 1 ) were developed with a predicted optimal annealing temperature of $63^{\circ} \mathrm{C}$. For each of the targeted Aphelenchoides species, the closest nontargets (Table 1) were identified by changing the mismatch settings in ARB as described in Neilson et al. (21).

To test the specificity of the primers, bacterial clones harboring a TOPO TA vector with an SSU rDNA fragment of the closest nontarget species were grown at $37^{\circ} \mathrm{C}$ in $2 \mathrm{ml}$ of Luria-Bertani medium supplemented with ampicillin at $100 \mu \mathrm{g} / \mathrm{ml}$. Plasmid extraction was performed using the Wizard Plus Minipreps DNA Purification System (Promega, Madison, WI). DNA concentrations were measured with a NanoDrop spectrophotometer (Thermo Scientific) and adjusted to $10 \mathrm{ng} / \mu \mathrm{l}$. For the qualitative nematode detection testing, $3 \mu \mathrm{l}$ of $10^{3} \times$ diluted sample was used.

For each quantitative PCR reaction, $3 \mu$ l of diluted template was mixed with species-specific primers (end concentrations for both primers $200 \mathrm{nM}$ ) and $12.5 \mu \mathrm{l}$ of Absolute SYBR Green fluorescein mix (Thermo Fisher, Wilmington, DE) in a total reaction volume of $25 \mu \mathrm{l}$. Thermal cycling was performed on iQ5 (Bio-Rad, Hercules, CA) and the following PCR profile was used: $95^{\circ} \mathrm{C}$ for $15 \mathrm{~min}$; followed by 60 cycles of $95^{\circ} \mathrm{C}$ for $30 \mathrm{~s}, 63^{\circ} \mathrm{C}$ (or gradient from 61 to $66^{\circ} \mathrm{C}$ ) for $1 \mathrm{~min}$, and $72^{\circ} \mathrm{C}$ for $30 \mathrm{~s}$. For negative controls, template was replaced by an equal volume of Milli-Q water. Quantitative PCR output is expressed in $C_{t}$ values (cycle number) at which the reporter dye emission intensity crosses a predetermined threshold. Here, the $C_{t}$ threshold was set at 80 .

Quantitative detection of Aphelenchoides species. In order to produce standards to relate $C_{t}$ to number of target nematodes, quantitative series of microscopically identified nematodes were prepared: $1,5,10,50$, and 100 hand-picked individuals of each species were collected in a $0.2-\mathrm{ml}$ tube containing $25 \mu \mathrm{l}$ of Milli$\mathrm{Q}$ water. For lysis, an equal volume of lysis buffer as described by Holterman et al. (10) was added. Lysis took place in a Thermomixer (Eppendorf, Hamburg, Germany) at $65^{\circ} \mathrm{C}$ and $750 \mathrm{rpm}$ for $1 \mathrm{~h}$, followed by $5 \mathrm{~min}$ incubation at $100^{\circ} \mathrm{C}$. Three microliters of $50 \times$ diluted sample from each range was used for Q-PCR. As a positive control relevant plasmid DNA was used. See previous section for quantitative PCR conditions. Resulting data were used to define the slope and the $y$ intercept of the regression line describing the linear relationship between log (number of nematodes) and the corresponding $\mathrm{C}_{\mathrm{t}}$ values.

Aphelenchoides-free nematode suspensions used as nontarget backgrounds were extracted from freshly harvested narcissus bulbs with adhering soil (Flower Bulbs and Nursery Stock-PPO Lisse, The Netherlands). Suspensions were collected after incubation for 2 days in a mist chamber. Subsamples from suspension were checked microscopically for the absence of target Aphelenchoides species. Nontarget backgrounds $(\approx 1,000$ individuals for each of the background samples) included plant-parasitic and free-living nematodes.

\section{RESULTS}

SSU rDNA-based phylogenetic relationships among Aphelenchoididae. Phylogenetic analysis of 60 full-length SSU rDNA sequences from members of the family Aphelenchoididae (54 sequences) and its close relatives (6 sequences) gave rise to two major subclades (Fig. 1A and B). Notably, foliar nematodes do not constitute a monophyletic group as $A$. besseyi and $A$. ritzema- 


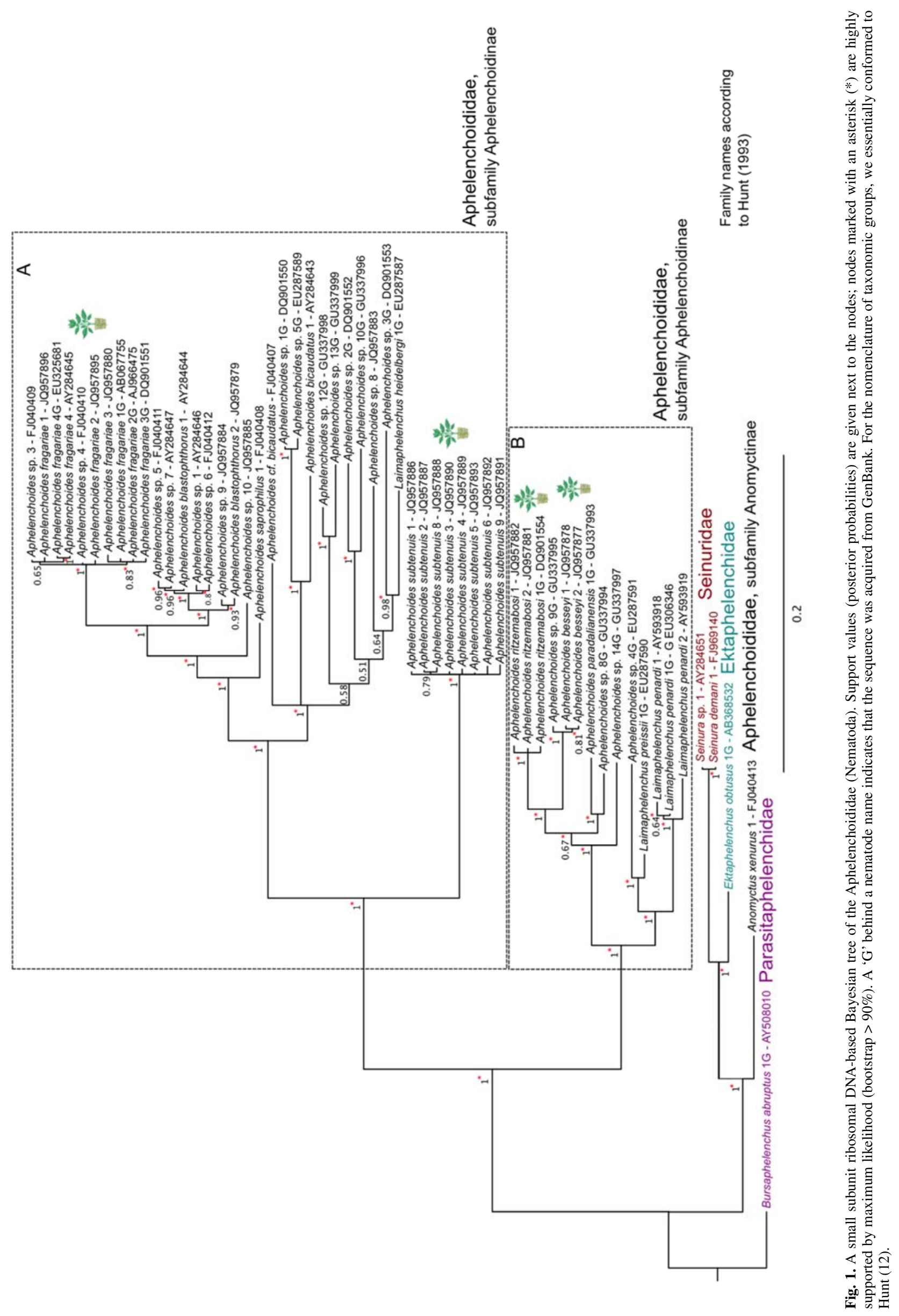

Vol. 102, No. 12, 20121155 
bosi, two major impact plant parasites, reside in a subclade (Fig. 1B), distinct from most other foliar nematode species (Fig. 1A). This division is supported by two independent phylogenetic methods, namely Bayesian inference and ML. Subclade B comprises a split between $A$. besseyi, A. ritzemabosi, and the recently described A. paradalianensis (4) on the one hand, and Laimaphelenchus preissii and $L$. penardi on the other. Subclade A is characterized by a sister relationship between A. subtenuis and representatives of other Aphelenchoides species (and L. heidelbergi). Other members of the superfamily Aphelenchoidoidea, namely Parasitaphelenchidae, Ektaphelenchidae, and Seinuridae, were used as outgroup. Noteworthy is the predatory nature of the Seinura spp., an unusual feeding type among the Aphelenchoidoidea; with rapid stylet thrusts it punctures the cuticle of its prey, after injection of pharyngeal gland secretions, the body content is ingested.

A remarkable characteristic of this Aphelenchoides phylogenetic tree is the inclusion of a relatively large number of sequences (number $=21$ ) for which the corresponding nematode could not be identified to species level. The group consists of 11 accessions from GenBank ("G" behind the name), and 10 accessions generated in this research (for example "Aphelenchoides sp. 2 "). This illustrates the paucity of informative characters for many species within this genus. In a few cases "Aphelenchoides sp." sequences reside within a well-supported monophyletic group with limited intraspecies variation. Aphelenchoides sp. 2, 3, and 4 are positioned within a cluster of $A$. fragariae sequences, and we assume that Aphelenchoides sp. 2, 3, and 4 in fact are representatives of this species. The same holds for Aphelenchoides sp. 9G, which is positioned in a small cluster of $A$. besseyi sequences. We assume that Aphelenchoides sp. 9G belongs to this species. A number of other "Aphelenchoides sp." sequences such as Aphelenchoides sp. $1 \mathrm{G}, 5 \mathrm{G}$, and $12 \mathrm{G}$ (etc.) could not be assigned to any Aphelenchoides species.

Although it is realized that a part of the Aphelenchoides biodiversity is not represented in this tree-and even this statement cannot be substantiated further due to poor description of many nominal species (12) — some foliar nematode species appeared as well-supported distinct groups with limited intraspecies variation in this SSU rDNA-based phylogenetic analysis. This prompted us

TABLE 1. Primer combinations and close nontarget sequences used in detection assays for four Aphelenchoides species: A. besseyi, A. fragariae, A. ritzemabosi, and A. subtenuis $^{\mathrm{a}}$

\begin{tabular}{lll}
\hline Target species & Primer combinations, positions, and product lengths & Closest nontargets \\
\hline A. subtenuis & 1454: $5^{\prime}$-gtagttggattgtctcgcc & Anomyctus xenurus 1 (FJ040413) \\
& Aphelenchoides ritzemabosi 1 \\
& Aphelenchoides ritzemabosi 2 \\
& Aphelenchoides sp. 10 \\
& Primer 1454 based on SNP at position 589 & Alaimus parvus 1 (AY284738) \\
Primer 1458 based on SNP at position 697 & Diplopeltula sp.1 (EF591329) \\
Product length: 144 bp & Granonchulus sp. 1 (AY593953) \\
& Heterodera goettingiana 1 (EU669915) \\
& Plectonchus sp. 1 (AY593920) \\
& Pratylenchus neglectus 1 (EU669923) \\
& Tylolaimophorus typicus 2 (JQ957901)
\end{tabular}

\section{A. besseyi \\ 1770: 5'-gcgggattcgtggttc*t 1772: $5^{\prime}$-cgacatgccgaaacatgag}

Primer 1454 based on SNP at position 1317 Primer 1458 based on SNP at position 1608 Product length: $325 \mathrm{bp}$
A. fragariae
1469: $5^{\prime}$-cttatcgcacgactttacg
1472: $5^{\prime}$-tcaaagtaatccgcatccaat
Without LNA
1844: $5^{\prime}$-ttatcgcacgactttacg
1847: $5^{\prime}$-caaagtaatccgcatccaat

Primer 1454 based on SNP at position 223 Primer 1458 based on SNP at position 655 Product length: $470 \mathrm{bp}$

A. ritzemabosi

1496: $5^{\prime}$-cgctggtgggtttcga

1499: 5'-ccegctaagaaatgatcac*c

Primer 1454 based on SNP at position 986

Primer 1458 based on SNP at position 1299

Product length: $347 \mathrm{bp}$
Acrobeloides cf thornei 1 (JQ957903)

Ascolaimus cf elongates 2 (EF591330)

Aphelenchoides ritzemabosi 2

Clavicaudoides trophurus 1 (AY284772)

Deladenus durus 1 (JQ957898)

Domorganus macronephritices 2 (FJ969122)

Ethmolaimus pratensis 1 (AY593942)

Panagrobelus stammeri 1 (AF202153)

Paracyatholaimus intermedius 3 (JQ957906)

Rotylenchus uniformis (AY593882)

Tripyla cf filicaudata 1 (AY284730)

Anomyctus xenurus 1 (FJ040413)

Anoplostoma sp. 2 (FJ040492)

Aphelenchoides sp. 8

Aphelenchoides cf bicaudatus 1

Aphelenchoides saprophilus 1

Aphelenchoides sp. 1

Aphelenchoides sp. 5

Pratylenchus penetrans 1 (EU669925)

Neopsilenchus magnidens 1 (AY284585)

Symplocostoma sp. 1 (FJ040502)

Anomyctus xenurus 1 (FJ040413)

Aphelenchoides composticola 1

Aphelenchoides sp. 8

Aphelenchoides sp. 10

Geomonhystera villosa 1 (EF591334)

Globodera sp. 4 (JQ957897)

Laimaphelenchus penardi 1

Ogma menzeli 1 (EU669919)

Oncholaimidae sp. 1 (FJ040493)

Paratylenchus straeleni 2 (AY284630)

Rotylenchus sp. 1 (AY284608)

Synonchiella sp. 1 (FJ040468)

Steinernema glaseri 2 (FJ040422)

\footnotetext{
${ }^{a}$ All primer combinations were tested in the annealing temperature of $63^{\circ} \mathrm{C}$. For the use of locked nucleic acids (LNAs), we essentially adhered to Nakitandwe et al. (20).
} 
to investigate whether this gene could be used for the molecular identification of four plant-parasitic Aphelenchoides species.

The use of SSU rDNA sequence motifs for the (quantitative) detection of four plant-parasitic Aphelenchoides species. A phylum-wide database comprising approximately 2,500 (nearly) full-length SSU rDNA sequences was used as a starting point to develop detection assays for four plant-parasitic Aphelenchoides species, namely A. besseyi, A. fragariae, A. ritzemabosi, and $A$. subtenuis. The software package ARB (14) was used to identify species-characteristic sequence motifs and close nontarget taxa for these particular fragments within the SSU rDNA. It is worth mentioning that these close nontargets are not necessarily systematically related to the target species. For the detection of $A$. besseyi, the most optimal primer combination (1770/1772, Table 1) was designed on the basis of two typical SSU rDNA motifs. As shown in Table 1, a series of nematode species was identified within the SSU rDNA database with similar motifs. Apart from $A$. ritzemabosi, this list includes taxa that are taxonomically unrelated to A. ritzemabosi such an Acrobeloides (Cephalobidae), an Ethmolaimus (Ethmolaimidae), a Panagrobelus (Panagrolaimidae), and a Rotylenchus (Hoplolaimidae) species (three bacterivores and one plant parasite, respectively).

Similarly, PCR primer combinations were developed for the other three selected Aphelenchoides species (Table 1). To optimize specificity, PCR primers were designed to work optimally at a high annealing temperature $\left(63^{\circ} \mathrm{C}\right)$. Moreover, all PCR primers have the same annealing temperature. As a consequence of this uniformity, these Aphelenchoides tests can be run in parallel in any combination.

In Figure 2A, the procedure for the testing of candidate Aphelenchoides species-specific primer combinations is illustrated. For detection of A. subtenuis, the annealing temperature characteristics were tested for primer combination 1454/1458 (Table 1) on plasmid DNA harboring the relevant SSU rDNA fragments. As can be seen in Figure 2A, the optimal temperature (the temperature giving the lowest $\mathrm{C}_{\mathrm{t}}$ value) is indeed $63^{\circ} \mathrm{C}$. Subsequently, the specificity of primer combination $1454 / 1458$ was tested with all relevant target species (cloned SSU rDNA fragments from three A. subtenuis populations) and 11 close nontarget species. As shown in Figure 2B1, none of the close nontarget species gave a significant PCR signal after 60 cycles. In Figure 2B2, the negative first derivative of the melting curve (temperature-dependent dissociation of the amplicon) is shown. It is noted that this particular amplicon gives rise to an asymmetric melting pattern.

To translate $C_{t}$ values into numbers of nematodes, a calibration curve was generated. To this end, a series of 1, 5, 10, 50, and 100 hand-picked $A$. subtenuis individuals was analyzed twice (technical replication). The results of the analyses with primer combination 1454/1458 is shown in Figure 2C. A robust linear relationship $\left(R^{2}=0.99\right)$ was found between $\mathrm{C}_{\mathrm{t}}$ values the $\log$ [number of target nematodes]. The relationship is characterized by a slope of $-5,437$ (slope is negative as more target DNA results in lower $C_{t}$ values), and an intercept $\left(C_{t}\right.$ value corresponding with a single target nematode) of 30.65 cycles. Values on the $x$ axis are negative as only a small fraction of the nematode lysate was used for analysis.

In essence, the same procedure was followed for $A$. besseyi, $A$. fragariae, and $A$. ritzemabosi. The selected primer combinations 1770/1772, 1469/1472 (1844/1847), and 1496/1499 (for primers see Table 1) were tested against 11,10 , and 13 close nontargets. The results are shown in Figure $3 \mathrm{~A} 1, \mathrm{~B} 1$, and $\mathrm{C} 1$. It was not always possible to design primers that give no detectable signal at all for all close nontargets. In case of the specificity test for $A$. fragariae, the gap between the latest target and the earliest nontarget signal is 29.3 cycles, which will be sufficient for most practical applications. In addition, the negative first derivatives of the melting curves are shown in Figure 3A2, B2, and C2.

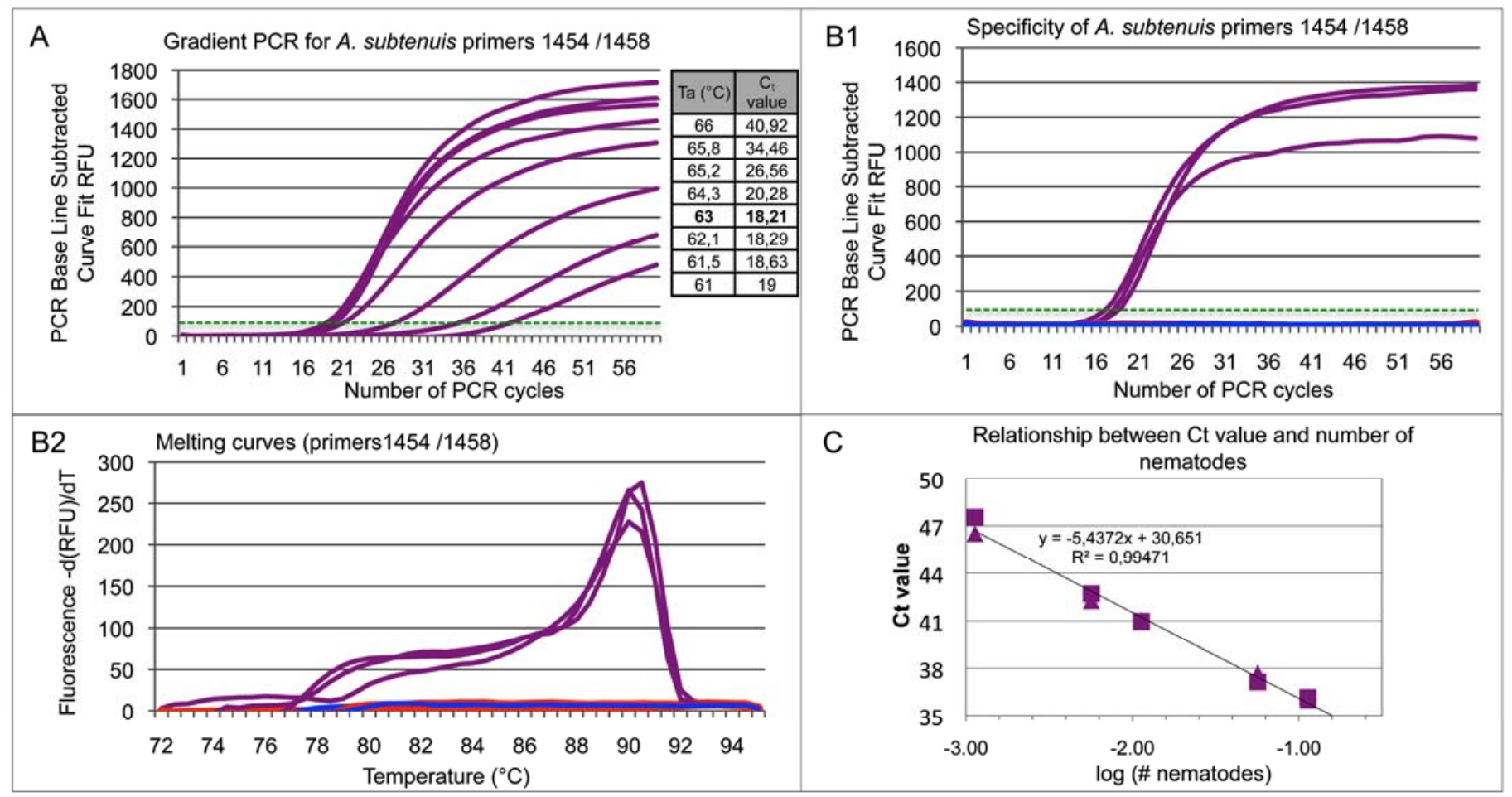

Fig. 2. Development of a foliar nematode-specific primer combination. Aphelenchoides subtenuis is used as an example to illustrate the procedure followed for primer development. A, All primers were designed to have optimal annealing temperature $\left(\mathrm{T}_{\mathrm{a}}\right)$ of $63^{\circ} \mathrm{C}$, with $\mathrm{C}_{\mathrm{t}}$ values rapidly increasing above target temperature plus $1{ }^{\circ} \mathrm{C}$. B1, Specificity test of an A. subtenuis primer combination with plasmid DNAs from three target species, small subunit ribosomal DNA fragments from 11 potential false positives (Table 1) and a negative water control. B2, Graph showing the negative first derivatives of the melting curve of the amplicons shown in B1. C, The relationship between $\mathrm{C}_{\mathrm{t}}$ values and numbers of nematodes for quantification of densities. Series of hand-picked individuals of A. subtenuis were lysed and amplified with primer combination 1454/1458. Two times five $\mathrm{C}_{\mathrm{t}}$ values were used to define the slope and the $y$ intercept of the regression line describing the linear relationship between $\log$ (number of nematodes) and the corresponding $\mathrm{C}_{\mathrm{t}}$ values. 
In several cases, locked nucleic acids (LNAs) were included to optimize primer specificity. For those who would prefer not to use LNAs, we tested whether conventional primers would give similar specificity. In the case of the A. fragariae primers 1469/1472, removal of a single nucleotide at the $5^{\prime}$ end resulted in primers $(1844 / 1847)$ with the same optimal annealing temperature $\left(63^{\circ} \mathrm{C}\right)$ and almost the same specificity (data not shown).

To further verify the specificity of the Aphelenchoides primers, target nematodes were added to Aphelenchoides-free nematode suspensions from soil. Twenty independent nematode suspensions that had been checked microscopically for the absence of Aphelenchoides spp. were used as backgrounds. For each experiment, five hand-picked target nematodes were added to the nematode suspension $(\approx 1,000$ individuals extracted narcissus bulbs with adhering soil), and after DNA extraction the newly developed SSU rDNA-based primers were used to check whether $A$. fragariae and $A$. ritzemabosi could be detected. In the $A$. fragariae-spiked samples, the target could be detected whereas $A$. ritzemabosi primers gave no signal at all (Table 2). In the $A$. ritzemabosi-spiked samples, the targets were always detected, but for three samples an A. fragariae signal was found as well (backgrounds 11, 13, and 14). The most plausible explanation for this result would be the presence of a small number of (probably one) A. fragariae individuals in the supposedly Aphelenchoides-free nematode suspension (with the detection assay presented here, a single $A$. fragariae gives a $\mathrm{C}_{\mathrm{t}}$ value around 37 cycles [data not shown]).

\section{DISCUSSION}

Foliar nematodes, plant-parasitic representatives of the genus Aphelenchoides, are problematic in more than one aspect. Although the genus receives most attention because of a few notorious plant parasites, by far most species are-from a plant production point of view-harmless fungivores. The distinction between foliar nematodes and fungal feeding Aphelenchoides species on the basis of morphological characteristics is often problematic. This is not only due to the absence of a reliable identification key for this genus, but also to the (very) poor description of numerous nominal species (12). To assess whether the SSU rDNA gene could be used for the molecular recognition of foliar nematode species, a phylogenetic analysis was made. The resulting tree showed a major, well-supported split among the foliar nematodes; whereas A. fragariae and A. subtenuis reside in

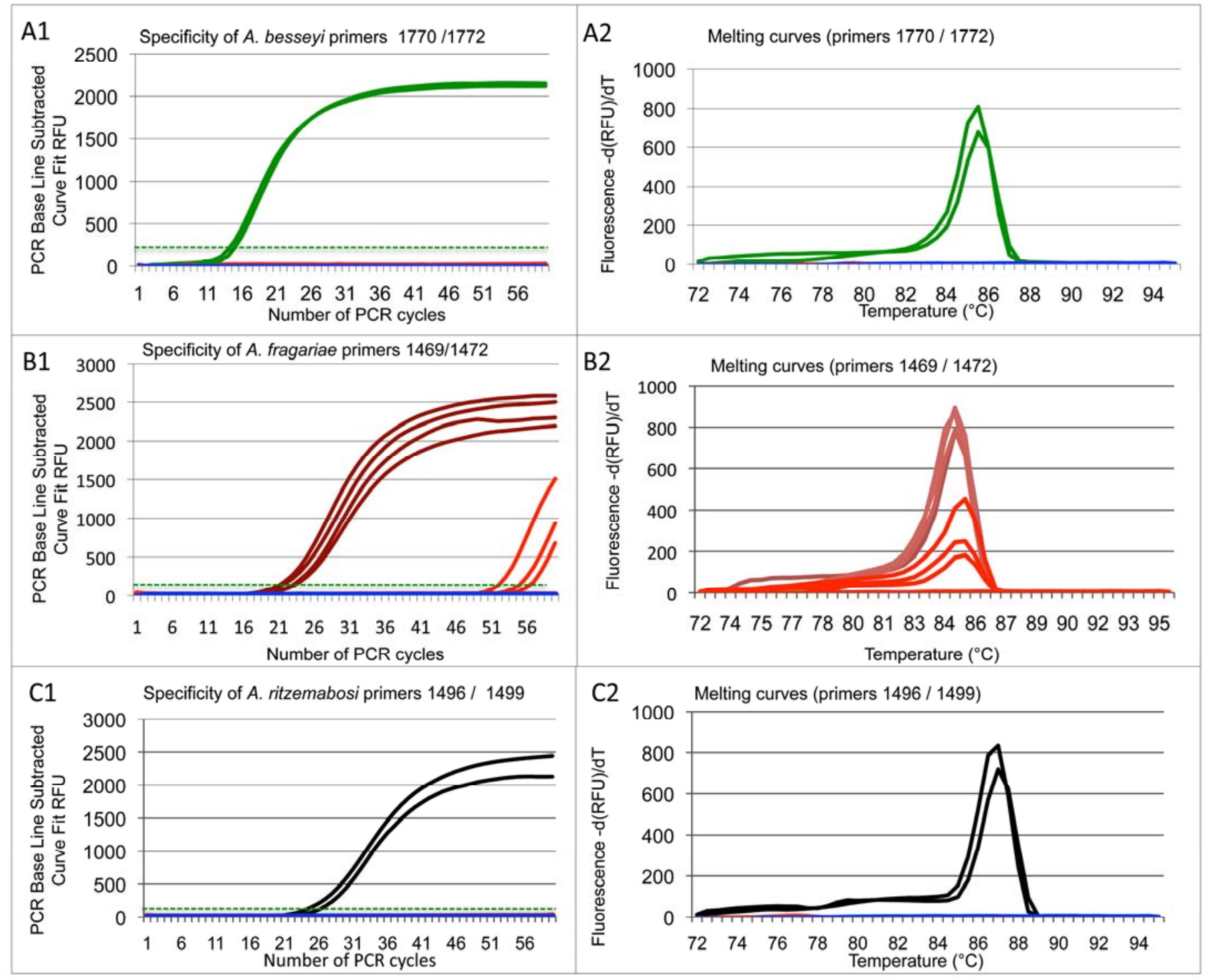

Fig. 3. Testing of polymerase chain reaction assays for the detection of three foliar nematode species. A1, Specificity test of an Aphelenchoides besseyi primer combination with plasmid DNAs from target and close nontarget species as given in Table 1, and $\mathbf{A 2}$, graph showing the negative first derivatives of the melting curve of the amplicons B1 and B2, idem for A. fragariae and $\mathbf{C 1}$ and $\mathbf{C 2}$, idem for A. ritzemabosi. 
subclade A, two other foliar nematode species, $A$. besseyi and $A$. ritzemabosi, are positioned in subclade B (Fig. 1). In two previous analyses with fewer representatives from this particular group a similar split has been observed. Based on 13 and 18 Aphelenchoides sequences, respectively, Chizhov et al. (3) and Van Megen et al. (26) mentioned two separate clades uniting the plantparasitic aphelenchids. A. subtenuis residing in a sister position vis-à-vis all other subclade $\mathrm{A}$ members, is known to infect roots, an atypical characteristic among the plant-parasitic Aphelenchoides species. The tail tip morphology seems to support the positioning of A. subtenuis. Except for A. bicaudatus, the Aphelenchoides species represented in subclade A all bear a single, poorly to well-developed mucro ("a sharp point at the end of, in this case, nematode's tail") devoid of any processes.

A remarkable feature of this phylogenetic tree is the positioning of two members of the predatory genus Seinura among fungivorous and plant-parasitic relatives. Upon puncturing the cuticle, the prey is immobilized by the injection of pharyngeal gland secretions, and the predigested body content is taken up. Possibly, Seinura is not the only predaceous nematode among the Aphelenchoidoidea as there is one report about $L$. penardi feeding on other nematodes (15).

Application of real-time PCR for the quantitative detection of plant-parasitic nematode species has rapidly gained popularity. Quantitative molecular assays have been developed for several high impact species such as Pratylenchus penetrans (24), $P$. thornei (27), the soybean cyst nematode Heterodera glycines (7), and the potato cyst nematodes Globodera rostochiensis (22) and G. pallida (19). All aforementioned assays are based on speciesspecific motifs in one of the two (noncoding) internal transcribed spacers (ITS1 or ITS2) located within the ribosomal DNA cistron. In a few occasions, authors selected coding regions; for the development of a quantitative assay for the pinewood nematode Bursaphelenchus xylophilus, Huang et al. (11) preferred the DNA topoisomerase I gene, whereas the SSU rDNA was shown to be suitable for the detection of the potato cyst nematode $G$. rostochiensis (10).

Ideally, molecular detection of plant-parasitic nematode species would be based on a DNA region showing minimal intraspecific

TABLE 2. To verify the specificity of the small subunit ribosomal DNA (SSU rDNA)-based primers, target nematodes were added to 20 independent Aphelenchoides-free nematode backgrounds (each $\approx 1,000$ nematodes) ${ }^{\mathrm{a}}$

\begin{tabular}{|c|c|c|c|c|}
\hline \multirow[b]{2}{*}{$\begin{array}{l}\text { Aphelenchoides } \\
\text { species }\end{array}$} & \multirow[b]{2}{*}{$\begin{array}{l}\text { Background } \\
\text { sample ID }\end{array}$} & \multirow{2}{*}{$\begin{array}{c}\text { Number } \\
\text { of target } \\
\text { nematodes }\end{array}$} & \multicolumn{2}{|c|}{ SSU rDNA-based detection } \\
\hline & & & $\begin{array}{c}\mathrm{C}_{\mathrm{t}} \\
\text { (A. fragariae) }\end{array}$ & $\begin{array}{c}\mathrm{C}_{\mathrm{t}} \\
\text { (A. ritzemabosi) }\end{array}$ \\
\hline A. fragariae & $\begin{array}{r}6 \\
7 \\
8 \\
9 \\
10 \\
35 \\
36 \\
37 \\
38 \mathrm{~A} \\
38 \mathrm{~B}\end{array}$ & 5 & $\begin{array}{l}34.00 \\
33.25 \\
33.09 \\
33.25 \\
32.57 \\
32.60 \\
32.72 \\
32.34 \\
32.31 \\
32.91\end{array}$ & $\begin{array}{l}\text { N/A } \\
\text { N/A } \\
\text { N/A } \\
\text { N/A } \\
\text { N/A } \\
\text { N/A } \\
\text { N/A } \\
\text { N/A } \\
\text { N/A } \\
\text { N/A }\end{array}$ \\
\hline A. ritzemabosi & $\begin{array}{l}11 \\
12 \\
13 \\
14 \\
15 \\
16 \\
17 \\
18 \\
19 \\
20\end{array}$ & 5 & $\begin{array}{c}37.67 \\
\text { N/A } \\
36.92 \\
37.22 \\
\text { N/A } \\
\text { N/A } \\
\text { N/A } \\
\text { N/A } \\
\text { N/A } \\
\text { N/A }\end{array}$ & $\begin{array}{l}34.33 \\
36.53 \\
36.26 \\
35.78 \\
35.40 \\
34.44 \\
35.39 \\
34.75 \\
34.24 \\
34.62\end{array}$ \\
\hline
\end{tabular}

a The background suspensions were extracted from narcissus bulbs with adhering soil. Individual nematode suspensions were checked microscopically for the absence of Aphelenchoides spp. and maximal interspecific variation. Hence, DNA regions that are used to study relationships among populations are less suitable for species detection. ITS regions were shown to be informative to study the relatedness between $G$. pallida populations $(2,8)$, isolates of the burrowing nematode Radopholus similis (6), and populations of the Columbia lance nematode Hoplolaimus (Basirolaimus) columbus (1). Hence, the use of the ITS regions for species detection purposes requires a thorough inventory of the intraspecific variation. This information would allow for the distinction between population and species-specific polymorphisms, and robust detection assays could be based on the latter. For foliar nematode species detection, we preferred to use an SSU rDNA, a relatively conserved coding region within the ribosomal DNA cistron with for these four Aphelenchoides species low intraspecific variation. We showed that this gene harbors sufficient informative nucleotide positions for real-time PCR-based detection, and the assays presented here are technically straightforward and easily implementable (i.e., requires standard laboratory equipment) in agricultural research and service and inspection laboratories.

\section{LITERATURE CITED}

1. Bae, C. H., Szalanski, A. L., and Robbins, R. T. 2009. Genetic variation of Hoplolaimus columbus populations in the United States using PCR-RFLP analysis of nuclear rDNA ITS regions. J. Nematol. 41:187-193.

2. Blok, V. C., Malloch, G., Harrower, B., Phillips, M. S., and Vrain, T. C. 1998. Intraspecific variation in Ribosomal DNA in populations of the potato cyst nematode Globodera pallida. J. Nematol. 30:262-274.

3. Chizhov, V. N., Chumakova, O. A., Subbotin, S. A., and Baldwin, J. G. 2006. Morphological and molecular characterization of foliar nematodes of the genus Aphelenchoides: A. fragariae and A. ritzemabosi (Nematoda: Aphelenchoididae) from the Main Botanical Garden of the Russian Academy of Sciences, Moscow. Russ. J. Nematol. 14:179-184.

4. Cui, R., Zhuo, K., Wang, H., and Liao, J. 2011. Aphelenchoides paradalianensis n. sp. (nematoda: Aphelenchoididae) isolated at Guangzhou, China, in packaging wood from South Korea. Zootaxa 2864:57-64.

5. De Ley, P., Decraemer, W., and Abebe, E. 2006. Introduction: Summary of present knowledge and research addressing the ecology and taxonomy of freshwater nematodes. Pages 3-30 in: Freshwater Nematodes, Ecology and Taxonomy. E. Abebe, I. Andrassy, and W. Traunspurger, eds. CABI Publishing, Wallingford, UK.

6. Elbadri, G. A. A., De Ley, P., Waeyenberge, L., Vierstraete, A., Moens, M., and Vanfleteren, J. 2002. Intraspecific variation in Radopholus similis isolates assessed with restriction fragment length polymorphism and DNA sequencing of the internal transcribed spacer region of the ribosomal RNA cistron. Int. J. Parasitol. 32:199-205.

7. Goto, K., Sato, E., and Toyota, K. 2009. A novel detection method for the soybean cyst nematode Heterodera glycines Ichinohe using soil compaction and real-time PCR. Nematol. Res. 39:1-7.

8. Grenier, E., Bossis, M., Fouville, D., Renault, L., and Mugniery, D. 2001. Molecular approaches to the taxonomic position of Peruvian potato cyst nematodes and gene pool similarities in indigenous and imported populations of Globodera. Heredity 86:277-290.

9. Hockland, S. 2004. Aphelenchoides besseyi. EPPO Bull. 34:303-308.

10. Holterman, M., van der Wurff, A., van den Elsen, S., van Megen, H., Bongers, T., Holovachov, O., Bakker, J., and Helder, J. 2006. Phylumwide analysis of SSU rDNA reveals deep phylogenetic relationships among nematodes and accelerated evolution toward crown clades. Mol. Biol. Evol. 23:1792-1800.

11. Huang, L., Ye, J. R., Wu, X. Q., Xu, X. L., Sheng, J. M., and Zhou, Q. X. 2010. Detection of the pine wood nematode using a real-time PCR assay to target the DNA topoisomerase I gene. Eur. J. Plant Pathol. 127:89-98.

12. Hunt, D. J. 1993. Aphelenchida, Longidoridae and Trichodoridae: Their Systematics and Bionomics. CAB International, Wallingford, UK.

13. Ibrahim, S. K., Perry, R. N., Burrows, P. R., and Hooper, D. J. 1994. Differentiation of species and populations of Aphelenchoides and of Ditylenchus angustus using a fragment of ribosomal DNA. J. Nematol. 26:412-421.

14. Ludwig, W., Strunk, O., Westram, R., Richter, L., Meier, H., Yadhukumar, Buchner, A., Lai, T., Steppi, S., Jobb, G., Forster, W., Brettske, I., Gerber, S., Ginhart, A. W., Gross, O., Grumann, S., Hermann, S., Jost, R., Konig, A., Liss, T., Lussmann, R., May, M., Nonhoff, B., Reichel, B., Strehlow, R., Stamatakis, A., Stuckmann, N., Vilbig, A., Lenke, M., Ludwig, T., Bode, A., and Schleifer, K. H. 2004. ARB: A software environment for sequence data. Nucleic Acids Res. 32:1363-1371. 
15. McBeth, C. W. 1937. Observations on a predacious nematode. Proc. Helminthol. Soc. Washington 4:18.

16. McCuiston, J. L., Hudson, L. C., Subbotin, S. A., Davis, E. L., and Warfield, C. Y. 2007. Conventional and pcr detection of Aphelenchoides fragariae in diverse ornamental host plant species. J. Nematol. 39:343355.

17. Mohammad Deimi, A., Tanha Maafi, Z., Palomares Rius, J. E., and Castillo, P. 2006. Aphelenchoides subtenuis (Cobb, 1926) Steiner \& Buhrer, 1932 (Nematoda: Aphelenchoididae) from Iran with morphological and morphometric characterisation. Nematology 8:903-908.

18. Mor, M., and Spiegel, Y. 1993. Infection of Narcissus Roots by Aphelenchoides subtenuis. J. Nematol. 25:476-479.

19. Nakhla, M. K., Owens, K. J., Li, W., Wei, G., Skantar, A. M., and Levy, L. 2010. Multiplex real-time PCR assays for the identification of the potato cyst and tobacco cyst nematodes. Plant Dis. 94:959-965.

20. Nakitandwe, J., Trognitz, F., and Trognitz, B. 2007. Reliable allele detection using SNP-based PCR primers containing locked nucleic acid: Application in genetic mapping. Plant Methods 3:2.

21. Neilson, R., Donn, S., Griffiths, B., Daniell, T., Rybarczyk, K. D., Van den Elsen, S., Mooyman, P., and Helder, J. 2009. Molecular tools for analysing nematode assemblages. Pages 188-207 in: Nematodes as Environmental Indicators. M. J. Wilson and T. Kakouli-Duarte, eds. CABI, Wallingford, UK.
22. Nowaczyk, K., Dobosz, R., Kornobis, S., and Obrepalska-Steplowska, A. 2008. TaqMan real-time PCR-based approach for differentiation between Globodera rostochiensis (golden nematode) and Globodera artemisiae species. Parasitol. Res. 103:577-581.

23. Rambaut, A., and Drummond, A. 2007. Tracer v1.4. http://beast. bio.ed.ac.uk/Tracer

24. Sato, E., Min, Y. Y., Shirakashi, T., Wada, S., and Toyota, K. 2007. Detection of the root-lesion nematode, Pratylenchus penetrans (Cobb), in a nematode community using real-time PCR. Jap. J. Nematol. 37:87-92.

25. Stamatakis, A. 2006. RAxML-VI-HPC: Maximum likelihood-based phylogenetic analyses with thousands of taxa and mixed models. Bioinformatics 22:2688-2690.

26. Van Megen, H., Van Den Elsen, S., Holterman, M., Karssen, G. Mooyman, P., Bongers, T., Holovachov, O., Bakker, J., and Helder, J. 2009. A phylogenetic tree of nematodes based on about 1200 full-length small subunit ribosomal DNA sequences. Nematology 11:927-950.

27. Yan, G., Smiley, R. W., and Okubara, P. A. 2012. Detection and quantification of Pratylenchus thornei in DNA extracted from soil using realtime PCR. Phytopathology 102:14-22.

28. Zhao, Z., Ye, W., Giblin-Davis, R. M., Li, D., Thomas, K. W., Davies, K. A., and Riley, I. T. 2008. Morphological and molecular analysis of six Aphelenchoides from Australian conifers and their relationship to Bursaphelenchus (Fuchs, 1937). Nematology 10:663-678. 